\title{
The Effect of Grandmothers' Presence on the
} Provision of Multidisciplinary Perinatal Support for
Pregnant and Postpartum Women with Psychosocial
Problems

This article was published in the following Dove Press journal:

Journal of Multidisciplinary Healthcare

Michi Ogawa,' Tasuku

Hashimoto, ${ }^{1,2}$ Mami Tanaka, ${ }^{3}$

Masumi Tachibana, (D) 'Ryota Seki, '

Aiko Sato, ${ }^{4}$ Jun Okayama, ${ }^{5}$ Mamiko

Endo, ${ }^{6}$ Naoki Saito, (iD) ${ }^{7}$ Yasunori

Sato, ${ }^{8}$ Hiroyuki Watanabe, (DD ${ }^{9,10}$

Michiko Nakazato, , I I Emi

Mori, (D) ${ }^{12}$ Makio Shozu, (ID) ${ }^{13}$

Masaomi lyo iD

'Department of Psychiatry, Graduate School of Medicine, Chiba University, Chiba, Japan; ${ }^{2}$ Department of Psychiatry, Satsuki-kai

Sodegaura-Satsukidai Hospital, Chiba, Japan

${ }^{3}$ Center for Forensic Mental Health, Chiba

University, Chiba, Japan; ${ }^{4}$ Department of

Psychiatry, Chiba University Hospital, Chiba,

Japan; ${ }^{5}$ Department of Maternal-Fetal

Medicine, Chiba University Hospital, Chiba,

Japan; ${ }^{6}$ Department of Pediatrics, Graduate

School of Medicine, Chiba University, Chiba,

Japan; ${ }^{7}$ Department of Legal Medicine,

Graduate School of Medicine, Chiba

University, Chiba, Japan; ${ }^{8}$ Department of

Preventive Medicine and Public Health, School

of Medicine, Keio University, Tokyo, Japan;

${ }^{9}$ Division of Medical Treatment and

Rehabilitation, Center for Forensic Mental

Health, Chiba University, Chiba, Japan;

${ }^{10}$ Department of Psychiatry, Gakuji-kai

Kimura Hospital, Chiba, Japan; "'Department

of Psychiatry, International University of

Health and Welfare Atami Hospital, Atami,

Japan; ${ }^{2}$ Department of Health Promotion

Nursing, Graduate School of Nursing, Chiba

University, Chiba, Japan; ${ }^{13}$ Department of

Reproductive Medicine, Graduate School of

Medicine, Chiba University, Chiba, Japan

Correspondence: Tasuku Hashimoto Department of Psychiatry, Chiba University

Graduate School of Medicine, I-8-I

Inohana, Chuo-ku, Chiba 260-8670, Japan

Tel +8I-43-226-2I48

Fax +8I-43-226-2I50

Email t-hashimoto@faculty.chiba-u.jp
Background: Pregnant and postpartum women with psychosocial problems are prone to face limited or absent perinatal functional support from biological grandmothers due to familial dysfunction. The study aimed to investigate whether the involvement and presence of biological maternal grandmothers providing practical support for their pre/postnatal daughters (ie, pregnant women) during the perinatal period may influence the number of support services provided by multidisciplinary agencies, including child consultation centers and municipal offices.

Participants and methods: This is a retrospective cohort study based on the medical records of all pregnant women with psychosocial problems that visited, gave birth, and received intervention from the hospital-based child protection unit at the Chiba University Hospital between February 2018 to March 2019. The primary outcome was to identify whether there was a difference in the number of multidisciplinary agencies providing perinatal support between pregnant women with and without the presence of functional support from biological maternal grandmothers during the perinatal period.

Results: We identified 114 pregnant and postpartum women with psychosocial problems. Seventy-six of these participants $(66.7 \%)$ had functional support from their biological maternal grandmothers during the perinatal period, and 38 participants $(33.3 \%)$ did not. The number of agencies involved with participants who lacked functional support was significantly higher than participants with functional support $(t(55.14)=2.98, p<0.01)$. This finding was consistent among pregnant and postpartum primipara participants $(\mathrm{n}=70)$ $(\mathrm{t}(68)=3.87, p<0.001)$, but not multipara $(\mathrm{n}=44)$.

Conclusion: The findings indicate that the presence and functional support of biological maternal grandmothers influence the support that is needed from multidisciplinary perinatal support systems by pregnant and postpartum women with psychosocial problems. Primipara mothers without support from their own mothers may need greater multidisciplinary support.

Keywords: child maltreatment, grandmother, perinatal, postpartum, pregnancy, psychosocial

\section{Introduction}

Family functioning largely influences antenatal care support, postnatal parenting, and maternal and perinatal mental health, including postpartum depression during pregnancy, childbirth, and childcare. In particular, the presence of a biological maternal grandmother is necessary not only for perinatal women with psychosocial problems but 
also for healthy people. ${ }^{1-4}$ Poor family functioning due to various psychosocial problems could consequently lead to perinatal maternal mental health problems as well as issues in child development and mother-infant attachment. Pregnant and postpartum women with psychosocial problems typically face the functional consequences of absent or limited perinatal support from biological maternal grandmothers due to family dysfunction (eg, parental divorce, ${ }^{5}$ lone motherhood, ${ }^{6,7}$ poverty, ${ }^{8,9}$ teenage parenting, ${ }^{10}$ history of severe mental illness, ${ }^{1,11}$ and child maltreatment ${ }^{12}$ ). Multidisciplinary familial support (eg, nurse's home visits, interventions from children's consultation offices) for pregnant and postpartum women with psychosocial problems and their children from dysfunctional families are necessary during the prenatal and postnatal period, ${ }^{13,14}$ but require substantial human and financial resources. ${ }^{15}$ Thus, in the context of limited resources, determining which pre/postnatal women with psychosocial problems should be prioritized in the provision of comprehensive multidisciplinary support services is critical.

In terms of family functioning on antenatal care support and postnatal parenting, the pregnant women's mothers (ie, biological maternal grandmothers) play a crucial role in providing support for maternal caregiving in terms of the psychosocial aspects, irrespective of the distance between living locations. ${ }^{3,4}$ Indeed, grandmothers' functional presence influences infant parenting, ${ }^{16,17}$ breastfeeding support, ${ }^{18}$ and intergenerational relationships (eg, grandmother-mother ${ }^{4,17}$ ) of pregnant and postpartum women and their children.

This study aims to investigate whether the functional presence of biological maternal grandmothers involved in practical support of their pre- and postnatal daughters (ie, pregnant women) during the perinatal period would influence the number of agencies that provide multidisciplinary support services for women, such as regional child consultation centers, municipal offices, and public health centers. To examine this, we conducted a retrospective survey of the agencies that served as multidisciplinary perinatal support providers for pregnant and postpartum women with psychosocial problems.

\section{Participants and Methods Study Design and Participants}

This is a retrospective cohort study based on the medical records of all consecutive pregnant women with psychosocial problems that met the following inclusion criteria: 1) continuously visited and gave birth at the department of maternal-fetal medicine, at the Chiba University Hospital between February 2018 to March 2019; and 2) received an intervention from the hospital-based child protection team (CPT), which plays a crucial role in the management of abused or neglected children and their abusive or negligent families. ${ }^{19}$ Hospital-based CPTs were not only proactively involved in cases of child maltreatment but also during the prenatal period for pregnant women with psychosocial problems, who are, along with their partners and families, at risk of engaging in child maltreatment. ${ }^{19}$ At Chiba University Hospital, midwives and obstetricians screen all pregnant women during their first visit to determine the presence of any psychosocial problems using clinical interviews and a questionnaire sheet regarding their medical and sociodemographic information as a part of the study recruitment. If a pregnant woman and her family are identified as having psychosocial problems, such as a history of severe mental illness and a lack of any social support, the hospitalbased CPT shared information about the case with the researchers. The exclusion criteria included pregnant women that 1) were transferred to other hospitals before giving birth or 2) had a stillbirth pregnancy.

In this study, we hypothesized that the functional involvement of maternal grandmothers in their daughters' prenatal care support and postnatal parenting would represent a crucial factor in determining the extent to which the multidisciplinary perinatal support system is involved with mothers and families that face psychosocial difficulties as a means of protecting mothers and preventing child maltreatment.

\section{Data Collection}

The data obtained from the medical records of the participants (ie, pregnant women) detailed their sociodemographic characteristics, family structure and caregiving capacity, medical information, obstetric information, and the multidisciplinary agencies involved with the mother and family during the perinatal period. Sociodemographic characteristics included age, medical insurance, and welfare public assistance. Family structure and caregiving capacity included marital status and living with partner, place and time of grandmother's support (eg, living with maternal grandmother before or after childbirth; living in mother's house with grandmother's support; and living in mother's house with no grandmother's support), individuals who were sources of support (eg, partner, maternal grandmother, maternal grandfather, paternal grandparents). The medical information included medical complications and psychiatric diseases. Obstetric information included the number of past 
pregnancies (primigravida or multipara), pregnancy complications, twin or more pregnancy, and fetal abnormalities. Agencies involved (during the perinatal period) indicated the presence of active support from organizations for pregnant and postpartum women and their infants (eg, home visits by public health nurses and the child counseling center).

\section{Defining Participants with and without Grandmothers' Perinatal Support}

In this study, participants with grandmothers' perinatal support were defined as those who received substantial help from their biological mothers regardless of whether they also received support from other family members, such as their partners and mothers-in-low. Participants without grandmothers' perinatal support were defined as those who did not receive any help from their biological mothers irrespective of support received from other family members.

\section{Defining the Multidisciplinary Agencies Involved with the Participants}

In the present study, multidisciplinary agencies were defined as those organizations which: (1) were involved with participants to provide support to perinatal women and/or protect their children from child maltreatment during the perinatal period; (2) did not employ any of the hospital staff and the hospital-based CPT's members; (3) were a facility independent of the hospital; and (4) did not have any conflict of interest with the hospital. Specifically, multidisciplinary agencies involved with the participants included regional child consultation centers committed to child protection, children and family divisions of municipal offices, public health centers that employ public health nurses, and certified facilities for postpartum care services.

\section{Primary and Secondary Outcomes}

The primary outcome of this study was to identify the differences in the number of agencies involved in providing multidisciplinary perinatal support between pregnant women with the functional presence of biological maternal grandmothers that practically support their daughters and their grandchildren during that perinatal period and without such support. The secondary outcome was to examine whether there was a difference in the number of multidisciplinary agencies involved between pregnant and postpartum primipara (ie, first pregnancy) and multipara (ie, multiple experiences giving birth) women.

\section{Statistical Analyses}

Statistical analyses were performed using the SPSS 19.0J software program (SPSS Inc., Chicago, IL, USA); for all statistical tests, $p$-values $<0.05$ were considered significant. Student's $t$-tests were performed for all continuous variables, including primary and secondary outcomes, whereas the chi-square or Fisher's exact tests were used for categorical variables.

\section{Ethical Considerations}

The study protocol was approved by the Ethics Committee of the Graduate School of Medicine at Chiba University in Chiba City, Japan (ID 3498). The committee waived the requirement for approval and written informed consent for patient participation in this study because the present study was the retrospective nature with only using the anonymized data to maintain the privacy of the participants with confidentiality. The information about this study was disclosed on the website of the Department of Psychiatry, Graduate School of Medicine, Chiba University using the opt-out method. The present study was conducted in accord with the Helsinki Declaration.

\section{Results}

\section{Participant Characteristics}

Table 1 details the characteristics of the participants of this study. A total of 114 participants were recruited during the survey period. From the overall sample, 76 participants $(66.7 \%)$ received functional support from their biological maternal grandmothers (during the perinatal period) while 38 participants (33.3\%) did not (Table 1$)$. The mean age of participants with grandmother perinatal support was significantly higher than participants without it (Table 1). Yet there were no differences in the number of children (including unborn babies) and marital status between these groups (Table 1). One prominent feature of the perinatal problems found in this study was that numerous participants suffered from mental disorders, particularly mood disorders (Table 1). Table 1 also details other social problems a few participants faced, including divorce during pregnancy $(n=1)$, arrest due to illegal drug use $(\mathrm{n}=1)$, use of mother and child shelter due to domestic violence $(\mathrm{n}=1)$, and decision to adopt child before delivery $(n=1)$. Incidentally, all said participants did not receive grandmothers' perinatal support. As a distinct feature of multidisciplinary agencies, public health nurses were involved with almost all participants. 
Table I Clinical Characteristics of Participants with and without Grandmothers' Perinatal Support

\begin{tabular}{|c|c|c|c|c|}
\hline Characteristics & $\begin{array}{l}\text { With Grandmothers' } \\
\text { Perinatal Support } \\
(n=76)\end{array}$ & $\begin{array}{l}\text { Without Grandmothers' } \\
\text { Perinatal Support } \\
(n=38)\end{array}$ & $t$ & $\mathbf{p}^{*}$ \\
\hline Age, Years [Mean (SD)] & $30.67 \pm 5.93$ & $33.84 \pm 7.62$ & 2.44 & 0.016 \\
\hline Number of Children (Including Unborn Babies), [Mean \pm & $1.47 \pm 0.74$ & $1.74 \pm 0.92$ & 1.65 & 0.10 \\
\hline SD] & n (\%) & n (\%) & $\chi^{2}$ & $p^{*}$ \\
\hline $\begin{array}{l}\text { Marital Status } \\
\text { Single } \\
\text { Married } \\
\text { Divorced (single) }\end{array}$ & $\begin{array}{l}12(16.0) \\
60(80.0) \\
3(4.0)\end{array}$ & $\begin{array}{l}6(15.8) \\
32(84.2) \\
0(0.0)\end{array}$ & 1.58 & 0.45 \\
\hline $\begin{array}{l}\text { Health Problems } \\
\text { Mental Disorders (ICD-10) } \\
\text { FI0-FI9: Mental and behavioral disorders due to psychoactive } \\
\text { substance use } \\
\text { F20-F29: Schizophrenia, schizotypal, and delusional disorders } \\
\text { F30-F39: Mood [affective] disorders } \\
\text { F40-F48: Neurotic, stress-related, and somatoform disorders } \\
\text { F50-F59: Behavioral syndromes associated with physiological } \\
\text { disturbances and physical factors } \\
\text { F60-F69: Disorders of adult personality and behavior } \\
\text { F70-F79: Mental retardation (intellectual disability) }\end{array}$ & $\begin{array}{l}50(65.8) \\
2(4.6) \\
3(6.8) \\
29(65.9) \\
9(20.5) \\
0(0.0) \\
0(0.0) \\
1(2.2)\end{array}$ & $\begin{array}{l}\text { I8(47.4) } \\
I(4.8) \\
6(28.6) \\
9(42.9) \\
I(4.8) \\
2(9.5) \\
I(4.8) \\
I(4.8)\end{array}$ & & \\
\hline $\begin{array}{l}\text { Medical Complications } \\
\text { Syphilis } \\
\text { Hepatitis B } \\
\text { HIV carrier } \\
\text { Ulcerative colitis } \\
\text { Cerebrovascular disease } \\
\text { Epilepsy } \\
\text { Narcolepsy } \\
\text { Collagen diseases } \\
\text { Genital warts } \\
\text { Marfan syndrome } \\
\text { Type I diabetes } \\
\text { Type } 2 \text { diabetes } \\
\text { Chronic kidney disease } \\
\text { Ovarian tumor } \\
\text { Uterine fibroid } \\
\text { Arrhythmia } \\
\text { Congenital cardiac anomaly } \\
\text { Endocrine disease }\end{array}$ & $\begin{array}{l}I(I .3) \\
0(0.0) \\
0(0.0) \\
I(I .3) \\
3(4.0) \\
3(4.0) \\
2(2.6) \\
I(I .3) \\
I(I .3) \\
0(0.0) \\
2(2.6) \\
2(2.6) \\
I(I .3) \\
0(0.0) \\
3(4.0) \\
0(0.0) \\
I(I .3) \\
0(0.0)\end{array}$ & $\begin{array}{l}2(5.3) \\
I(2.6) \\
I(2.6) \\
0(0.0) \\
0(0.0) \\
I(2.6) \\
0(0.0) \\
I(2.6) \\
0(0.0) \\
I(2.6) \\
0(0.0) \\
0(0.0) \\
0(0.0) \\
I(2.6) \\
I(2.6) \\
I(2.6) \\
0(0.0) \\
3(7.9)\end{array}$ & & \\
\hline $\begin{array}{l}\text { Obstetric Complications Including Fetal Abnormalities } \\
\text { Gestational diabetes } \\
\text { Hypertension during pregnancy } \\
\text { Threatened premature delivery } \\
\text { Weak labor } \\
\text { Premature rupture of the membranes } \\
\text { Breech presentation } \\
\text { Placenta previa/Low Lying Placenta }\end{array}$ & $\begin{array}{l}\text { II (I4.5) } \\
2(2.6) \\
4(5.3) \\
3(4.0) \\
6(7.9) \\
4(5.3) \\
2(2.6)\end{array}$ & $\begin{array}{l}4(I 0.5) \\
I(2.6) \\
3(7.9) \\
I(2.6) \\
3(7.9) \\
I(2.6) \\
I(2.6)\end{array}$ & & \\
\hline
\end{tabular}

(Continued) 
Table I (Continued).

\begin{tabular}{|c|c|c|c|c|}
\hline Characteristics & $\begin{array}{l}\text { With Grandmothers' } \\
\text { Perinatal Support } \\
(n=76)\end{array}$ & $\begin{array}{l}\text { Without Grandmothers' } \\
\text { Perinatal Support } \\
(\mathrm{n}=38)\end{array}$ & $t$ & $\mathbf{p}^{*}$ \\
\hline $\begin{array}{l}\text { Placenta accreta } \\
\text { Premature separation of normally implanted placenta } \\
\text { Fetal malformation } \\
\text { Intrauterine growth restriction } \\
\text { Cervical incompetency } \\
\text { Cephalopelvic disproportion } \\
\text { Incompatibility of maternal and fetal blood group type } \\
\text { Oligohydramnios } \\
\text { Polyhydramnios } \\
\text { Twins } \\
\text { Forelying of the umbilical cord } \\
\text { Atonic bleeding } \\
\text { Arrest of labor } \\
\text { Fetal hydrops }\end{array}$ & $\begin{array}{l}\mathrm{I}(\mathrm{I} .3) \\
\mathrm{I}(\mathrm{I} .3) \\
\mathrm{I}(\mathrm{I} .3) \\
0(0.0) \\
3(4.0) \\
\mathrm{I}(\mathrm{I} .3) \\
0(0.0) \\
\mathrm{I}(\mathrm{I} .3) \\
\mathrm{I}(\mathrm{I} .3) \\
3(4.0) \\
\mathrm{I}(\mathrm{I} .3) \\
\mathrm{I}(\mathrm{I} .3) \\
\mathrm{I}(\mathrm{I} .3) \\
\mathrm{I}(\mathrm{I} .3)\end{array}$ & $\begin{array}{l}0(0.0) \\
\mathrm{I}(2.6) \\
\mathrm{I}(2.6) \\
\mathrm{I}(2.6) \\
0(0.0) \\
\mathrm{I}(2.6) \\
2(5.3) \\
\mathrm{I}(2.6) \\
0(0.0) \\
3(7.9) \\
0(0.0) \\
0(0.0) \\
0(0.0) \\
0(0.0)\end{array}$ & & \\
\hline $\begin{array}{l}\text { Economic Problems } \\
\text { Suspected abuse against newborn or children } \\
\text { Receiving welfare public assistance } \\
\text { Lack of any social support before multidisciplinary agencies } \\
\text { Other social problems }\end{array}$ & $\begin{array}{l}I(I .3) \\
2(2.7) \\
7(9.2) \\
0(0.0)\end{array}$ & $\begin{array}{l}2(5.2) \\
3(7.9) \\
11(29.0) \\
4(10.5)\end{array}$ & & \\
\hline $\begin{array}{l}\text { Intervention and Support from Multidisciplinary Agencies } \\
\text { Public health nurse } \\
\text { Municipality } \\
\text { Child counseling center } \\
\text { Area meeting for child protection measures } \\
\text { Neuvola } \\
\text { Postnatal care } \\
\text { Family and child counseling center } \\
\text { Police agency } \\
\text { Home caregiver } \\
\text { Psychiatric nurse home visit } \\
\text { Area living support center }\end{array}$ & $\begin{array}{l}72(94.7) \\
7(9.2) \\
10(13.3) \\
0(0.0) \\
2(2.6) \\
I(1.3) \\
7(9.2) \\
I(1.3) \\
2(2.6) \\
2(2.6) \\
I(1.3)\end{array}$ & $\begin{array}{l}35(92.1) \\
6(16.2) \\
10(27.0) \\
\mathrm{I}(2.6) \\
\mathrm{I}(2.6) \\
5(13.2) \\
5(13.2) \\
\mathrm{I}(2.6) \\
\mathrm{I} 0(26.3) \\
\mathrm{I}(2.6) \\
\mathrm{I}(2.6)\end{array}$ & & \\
\hline
\end{tabular}

Notes: Participants with grandmothers' perinatal support were defined as those who received substantial help from their biological mothers regardless of whether or not they did it from their other family members such as their partners and mothers-in-low. Participants without grandmothers' perinatal support were defined as those who did not receive any help from their biological mothers irrespective of other family members' support. * $p$-value was calculated for the results of the $t$-test or $\chi^{2}$-test.

\section{Agency Involvement and Functional Support} In this study, the range of numbers of agencies involved with participants was 0 to 4 except for the hospital-based CPT. To compare differences in the two groups (with and without functional from their biological maternal grandmothers) regarding the number of multidisciplinary agencies involved with the participants, we performed a Student's $t$-test after controlling for medical and obstetric complications. Figure 1 depicts the number of multidisciplinary agencies involved with pregnant women with psychosocial problems between participants with and without functional from their biological maternal grandmothers. The number of agencies involved with participants who lacked functional support was significantly higher than for those participants with functional support $(t(55.14)=2.98, p<0.01)($ Figure 1$)$.

\section{Agency Involvement, Primipara/Multipara Mothers, and Functional Support}

Table 2 shows the numbers of primiparas and multiparas among the participants. Among pregnant and postpartum primipara participants $(n=70)$, the number of agencies involved with the participants who did not have functional 


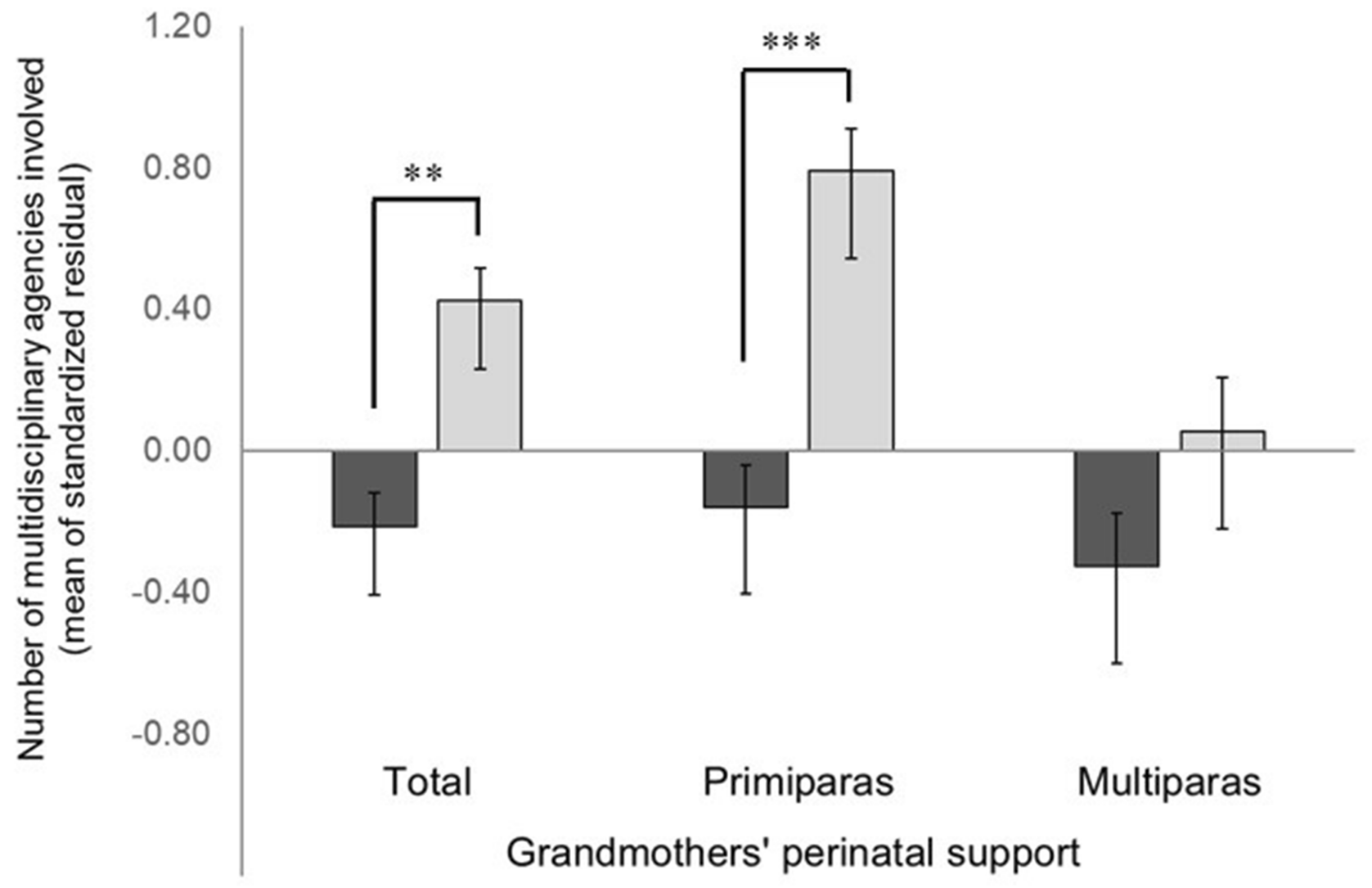

$\square$ With grandmother's perinatal support
$\square$ Without grandmother's perinatal support

Figure I Number of multidisciplinary agencies involved with participants.

Notes: Participants with grandmothers' perinatal support were defined as those who received substantial help from their biological mothers regardless of whether they did it from their other family members such as their partners and mothers-in-low. Participants without grandmothers' perinatal support were defined as those who did not receive any help from their biological mothers irrespective of other family members' support. A student's $t$-test was performed after controlling the medical complications and the obstetric complications. The number of agencies involved with participants without functional support was significantly higher than participants with functional support $(t(55.14)=2.98, p<0.01)$. Among pregnant and postpartum primipara participants $(n=70)$, the number of agencies involved with those participants without functional support were significantly higher than for those participants with functional support $(t(68)=3.87, p<0.001)$. Error bars represent standard error of the mean. $* * p<0.01$, *** $p<0.001$.

support was significantly higher than for the participants with functional support $(t(68)=3.87, p<0.001)$ (Figure 1). Among multipara participants $(n=44)$, there were no significant differences in the number of agency involvement between participants with and without functional support from their biological maternal grandmothers (Figure 1).

\section{Discussion}

This study yielded two important findings. First, multidisciplinary agencies were more involved in pregnant women with psychosocial problems without functional support than pregnant women with functional support from their biological maternal grandmothers. Furthermore, it was also particularly evident that primipara mothers without functional support received more supportive involvement from multidisciplinary agencies than primipara mothers with functional support. Contrastingly, there was no significant difference in the involvement of multidisciplinary involvement in multipara mothers with and without functional support. This finding suggests that primipara mothers with psychosocial problems who lack functional support from their own mothers are at particular risk. Second, there were two prominent features 1) numerous cases of mothers diagnosed with psychiatric disorders, and 2) almost all pregnant women with psychological issues received supportive interventions by public health nurses in this study.

These initial findings demonstrate the lack of functional support from biological grandmothers for prenatal and 
Table 2 Parity and Grandmothers' Perinatal Support

\begin{tabular}{|c|l|l|l|l|}
\hline & $\begin{array}{l}\text { With } \\
\text { Grandmothers' } \\
\text { Perinatal } \\
\text { Support (n = } \\
\text { 76) }\end{array}$ & $\begin{array}{l}\text { Without } \\
\text { Grandmothers' } \\
\text { Perinatal } \\
\text { Support (n = 38) }\end{array}$ & $\chi^{2}$ & $\mathbf{p}^{*}$ \\
\cline { 2 - 4 } & $\mathbf{n}(\%)$ & $\mathbf{n}(\%)$ & 3.13 & 0.08 \\
\hline $\begin{array}{l}\text { Parity of } \\
\text { the Mother } \\
\text { Primipara } \\
\text { Multipara }\end{array}$ & $\begin{array}{l}5 \mathrm{I}(67.1) \\
25(32.9)\end{array}$ & $\begin{array}{l}19(50.0) \\
19(50.0)\end{array}$ & \\
\hline
\end{tabular}

Notes: Participants with grandmothers' perinatal support were defined as those who received substantial help from their biological mothers regardless of whether they did it from their other family members such as their partners and mothers-inlow. Participants without grandmothers' perinatal support were defined as those who did not receive any help from their biological mothers irrespective of other family members' support. * $p$-value was calculated for the results of the $\chi^{2}$-test.

postpartum daughters with psychosocial problems, particularly, primipara mothers, and thus requires increased support from multidisciplinary agencies during the perinatal period. The findings support our hypothesis that maternal grandmothers' functional involvement in their daughters' antenatal care support and postnatal parenting may be a crucial factor in determining the involvement of an intensive multidisciplinary support system in pregnant and postpartum women with psychosocial problems during the perinatal period. In a healthy functioning family, a woman develops throughout her life while being influenced by her relationship with her biological mother (ie, mother-daughter relationship). ${ }^{2}$ However, many pregnant women with psychosocial problems are likely to have endured painful experiences (eg, parental divorce, ${ }^{5}$ severe mental illness in themselves ${ }^{1}$ or parents, ${ }^{11}$ poverty, ${ }^{8,9}$ or child maltreatment ${ }^{12}$ ) throughout childhood and adolescence due to their dysfunctional family. Several pregnant women with psychosocial problems have not formed healthy mother-daughter relationships. As such, in the prenatal and postpartum periods, they will likely experience limited or absent functional support from their mothers (ie, biological maternal grandmothers) even during their first experience of pregnancy and child-rearing. Therefore, multidisciplinary perinatal support services that consist not only home visits by public health nurses, but also diverse multidisciplinary agencies involved in maternal and child health (eg, children's counseling office) should focus on perinatal women with psychosocial problems along with their children and families who are lacking the functional support of the biological maternal grandmother during the antenatal and postnatal period.
This study also shows that primipara, but not multipara women, without functional support received more support from multidisciplinary agencies than those with functional support from their biological maternal grandmothers. A recent prospective cohort study demonstrated that primiparas suffer from a higher level of fatigue compared to multiparas shortly after delivery. ${ }^{20}$ Another survey of the perinatal mother-daughter relationship showed that more primiparas require their mothers' perinatal help more relative to multipara women as parity is associated with the practical presence of grandmother perinatal support. ${ }^{4}$ In addition, the mother-daughter relationship changes from adolescence to adulthood, as do the developmental transitions of the mother-daughter relationship through the first pregnancy. ${ }^{3}$ However, relatively few cases of primiparas with psychosocial problems have difficulties with grandmother perinatal support due to various serious circumstances. Given these findings, primiparas with psychological problems from dysfunctional families might have little or no access to perinatal support from their mothers and are prone to face difficulties and crises in their mental and physical health, ability to rear their children and live independently of the early postpartum period. Interventions should target this high-risk population of pregnant and postnatal mothers with psychosocial problems with generous multidisciplinary perinatal support.

One major finding of this study was the fact that was numerous cases of mothers diagnosed with psychiatric disorders. Mental health problems (e.g., postpartum depression) are common during pregnancy and the postpartum period. ${ }^{21}$ Although pregnant women with psychological problems and their children are supposed to receive support from multidisciplinary healthcare systems, yet evidence-based models still have not demonstrated this. $^{13,22}$ Further studies are thus necessary to address this issue. In addition, another distinct finding was that virtually all participants received intervening visits by public health nurses in this study. Our finding is consistent with previous reports from Japan that indicated that public health nurses commonly intervene and aid pregnant women (and their children and families), as they are recognized to be at a high risk of engaging in child maltreatment during pregnancy and the postnatal period. ${ }^{13,23}$ As this system is commonplace in Japan, further studies are needed to functionally assess and evaluate the efficacy of public health nurses as key agents in the provision of multidisciplinary perinatal support and the prevention of child maltreatment. 


\section{Limitations}

There are some limitations to this study. First, this study was implemented at a single institute and then had a small sample size. Therefore, the psychosocial problems of the participants consisted of less child maltreatment and economic problems. A multicenter study with various regions should be needed to improve multidisciplinary perinatal health services. Second, the design of this study was retrospective. For acquiring more detail and valid data, a prospective study should be implemented. However, there may be some challenges with obtaining participants' agreement after informed consent among women with serious psychosocial problems, such as a history of arrest for felonies.

\section{Conclusions}

The study demonstrated the presence and involvement of biological maternal grandmothers during and after pregnancy is an important source of functional support for prenatal and postpartum daughters with psychosocial problems. It also showed that the lack of such support should be addressed by obliging the involvement of high-level multidisciplinary agencies during the perinatal period. The findings thus arguably provide evidence for the functional value of the presence of biological maternal grandmothers and suggest that the multidisciplinary perinatal support system should focus on pregnant and postpartum women with psychosocial problems, particularly, primipara women.

\section{Acknowledgments}

We would like to thank Editage (www.editage.jp) for English language editing. We declare that this work was financially supported by Satsuki-kai Sodegaura-Satsukidai Hospital, Japan. We would like to thank all the patients and doctors who participated in this study. We are particularly grateful to the clinical research nurses (Kaoru Ikeda, Chisako Fujishiro, and Chiharu Fujita), the research assistant (Komako Ito), and the members of CPT in Chiba University Hospital (Kyoko Tanabe, Ryoko Fukuhara, Saki Eshima, and Akiko Ichihara) for cooperating with this study at Chiba University Hospital.

\section{Author Contributions}

MO, TH, EM and MI designed this study. MO, RS, AS, MT and $\mathrm{TH}$ acquired data. MO, MT, and TH analyzed the data, and $\mathrm{TH}, \mathrm{MN}, \mathrm{YS}, \mathrm{EM}, \mathrm{HW}, \mathrm{MS}$, and MI interpreted the results. JO and MS made an evaluation of obstetrical and fetal outcomes. TH, JO, ME, NS made an assessment of child protection team as multidisciplinary support. $\mathrm{MO}$ and TH drafted the manuscript, and YS, EM, MS, HW, and MI revised the manuscript. MS, HW, EM and MI supervised the study. All authors contributed to data analysis, drafting or revising the article, gave final approval of the version to be published, and agree to be accountable for all aspects of the work.

\section{Funding}

This study was implemented by the financial support of Sodegaura-Satsukidai Hospital. The Foundation had no role in the study design; in the collection, analysis, and interpretation of data; in the writing of the report; or in the decision to submit the article for publication.

\section{Disclosure}

In accordance with Dove press policy and the authors' ethical obligation as researchers, we are reporting that Dr. Hashimoto reported personal fees from research support of a clinical trial that the Signant Health company manages. Dr. Iyo received consultant fees from Janssen, Eli Lilly, Otsuka, and Meiji Seika Pharma and reports honoraria from Janssen, Eli Lilly, Otsuka, Meiji Seika Pharma, Astellas, Dainippon Sumitomo, Ono, Mochida, MSD, Eisai, Daiichi-Sankyo, Novartis, Teijin, Shionogi, Hisamitsu, and Asahi Kasei. The other authors report no potential conflicts of interest in this work.

\section{References}

1. Rohder K, Nystrom-Hansen M, MacBeth A, et al. Antenatal caregiving representations among expectant mothers with severe mental illness: a cross-sectional study. J Reprod Infant Psychol. 2019;1-14.

2. Josselson RL. Revising Herself: The Story of Women's Identify from College to Midlife. New York: Oxford University Press; 1996.

3. Martell LK. The mother-daughter relationship during daughter's first pregnancy: the transition experience. Holist Nurs Pract. 1990;4 (3):47-55. doi:10.1097/00004650-199005000-00008

4. Iseki A, Ohashi K. Relationship in Japan between maternal grandmothers' perinatal support and their self-esteem. Nurs Health Sci. 2014;16(2):157-163. doi:10.1111/nhs.2014.16.issue-2

5. Mustonen U, Huurre T, Kiviruusu O, Haukkala A, Aro H. Long-term impact of parental divorce on intimate relationship quality in adulthood and the mediating role of psychosocial resources. J Fam Psychol. 2011;25(4):615-619.

6. Rousou E, Kouta C, Middleton N, Karanikola M. Single mothers' selfassessment of health: a systematic exploration of the literature. Int Nurs Rev. 2013;60(4):425-434.

7. Martin JA, Hamilton BE, Sutton PD, et al. Births: final data for 2005. Natl Vital Stat Rep. 2007;56(6):1-103.

8. Damaske S, Bratter JL, Frech A. Single mother families and employment, race, and poverty in changing economic times. Soc Sci Res. 2017;62:120-133. doi:10.1016/j.ssresearch.2016.08.008 
9. Adynski H, Zimmer C, Thorp J Jr., Santos HP Jr. Predictors of psychological distress in low-income mothers over the first postpartum year. Res Nurs Health. 2019;42(3):205-216. doi:10.1002/nur. v42.3

10. Unger DG, Cooley M. Partner and grandmother contact in black and white teen parent families. J Adolesc Health. 1992;13(7):546-552. doi:10.1016/1054-139X(92)90367-K

11. Granek L, Danan D, Bersudsky Y, Osher Y. Living with bipolar disorder: the impact on patients, spouses, and their marital relationship. Bipolar Disord. 2016;18(2):192-199. doi:10.1111/bdi.12370

12. Berthelot N, Lemieux R, Garon-Bissonnette J, Lacharite C, Muzik M. The protective role of mentalizing: reflective functioning as a mediator between child maltreatment, psychopathology and parental attitude in expecting parents. Child Abuse Negl. 2019;95:104065. doi:10.1016/j.chiabu.2019.104065

13. Tachibana Y, Koizumi N, Akanuma C, et al. Integrated mental health care in a multidisciplinary maternal and child health service in the community: the findings from the Suzaka trial. BMC Pregnancy Childbirth. 2019;19(1):58. doi:10.1186/s12884-019-2179-9

14. Armstrong KL, Fraser JA, Dadds MR, Morris J. A randomized, controlled trial of nurse home visiting to vulnerable families with newborns. $J$ Paediatr Child Health. 1999;35(3):237-244. doi:10.1046/j.1440-1754.1999.00348.x

15. Sword W. A socio-ecological approach to understanding barriers to prenatal care for women of low income. J Adv Nurs. 1999;29 (5):1170-1177.

16. Reid J, Schmied V, Beale B. 'I only give advice if I am asked': examining the grandmother's potential to influence infant feeding decisions and parenting practices of new mothers. Women Birth. 2010;23(2):74-80. doi:10.1016/j.wombi.2009.12.001
17. Arnold A, Lewis J, Maximovich A, Ickovics J, Kershaw T. Antecedents and consequences of caregiving structure on young mothers and their infants. Matern Child Health J. 2011;15 (7):1037-1045. doi:10.1007/s10995-010-0650-3

18. Grassley J, Eschiti V. Grandmother breastfeeding support: what do mothers need and want? Birth. 2008;35(4):329-335. doi:10.1111/ bir.2008.35.issue-4

19. Okato A, Hashimoto T, Tanaka M, et al. Hospital-based child protection teams that care for parents who abuse or neglect their children recognize the need for multidisciplinary collaborative practice involving perinatal care and mental health professionals: a questionnaire survey conducted in Japan. J Multidiscip Healthc. 2018;11:121-130. doi:10.2147/JMDH.S155352

20. Iwata H, Mori E, Sakajo A, Aoki K, Maehara K, Tamakoshi K. Course of maternal fatigue and its associated factors during the first 6 months postpartum: a prospective cohort study. Nurs Open. 2018;5 (2):186-196. doi:10.1002/nop2.130

21. Black RE, Victora CG, Walker SP, et al. Maternal and child undernutrition and overweight in low-income and middle-income countries. Lancet. 2013;382(9890):427-451. doi:10.1016/S0140-673 6(13)60937-X

22. NICE: the national institute for health and care excellence: antenatal and postnatal mental health: clinical management and service guidance [CG192]. Published date: December. 2014. Last update: April 2018. Avialable from: https:/www.nice.org.uk/guidance/cg192. Accssed December8, 2019.

23. Ninomiya T, Hashimoto H, Tani H, Mori K. Effects of primary prevention of child abuse that begins during pregnancy and immediately after childbirth. J Med Invest. 2017;64(1.2):153-159. doi:10. 2152/jmi.64.153
Journal of Multidisciplinary Healthcare

\section{Publish your work in this journal}

The Journal of Multidisciplinary Healthcare is an international, peerreviewed open-access journal that aims to represent and publish research in healthcare areas delivered by practitioners of different disciplines. This includes studies and reviews conducted by multidisciplinary teams as well as research which evaluates the results or conduct of such teams or healthcare processes in general. The journal covers a very wide range of areas and welcomes submissions from practitioners at all levels, from all over the world. The manuscript management system is completely online and includes a very quick and fair peer-review system. Visit http://www.dovepress.com/testimonials. php to read real quotes from published authors. 